\title{
Readjusting teaching instruments. Online dictionaries in the spotlight
}

\author{
Cristina Silvia VÂLCEA ${ }^{1}$
}

The recent world medical condition (COVID 19) has triggered unimaginable changes to a domain where changes are well thought of long before implementation and where advancements are slow and costly. The domain is none other than education which has found itself deprived of the most basic facilitator: physical presence of both teachers and pupils/students in classrooms. The response of the system to the medical crisis has been intuitive, at times individual, as it came down to each teacher's material and inner resources to find an advantageous solution for students. At the other end, lured by the possibility of spending extensive time on computers while attending classes, students have had different attitudes to learning and taking advantage of all the technological advances available. This article is a small-scale analysis of how the students understand to continue and deepen the study of foreign languages by retorting to online dictionaries which have been introduced as vital and indispensable tools in general and even more in times of medical insecurity.

Keywords: online dictionaries, learner's autonomy, pronunciation

\section{Education challenges in times of medical crisis}

This quantitative study addresses the students' interest in accessing online dictionaries which might be correlated to the students' exposure to online resources and dictionaries and their actual use of online dictionaries in particular and dictionaries in general. Facing the new challenges of online education generated by the COVID 19 pandemics, both teachers and learners have gone to great lengths to overcome the distance and the emotional difficulties that might have shown up. New teaching methods have been gradually developed and a new era in education has started. Whether both teachers and students have been ready to adjust to this new reality is still to be decided on, but this period has revealed that, now more than ever, learner autonomy has turned into an issue that needs

1 Transilvania University of Braşov, cristina.valcea@unitbv.ro 
more research into in order to find the best means of encouraging it and of furthering it. Certainly, that brings along a number of other questions that need to be addressed which refer to the redefinition of the school and teachers' role in the education of the youth. Or the question related to how to help develop student autonomy and how autonomous students should be still need to be dealt with.

In light of the above, this research tests engineering students' autonomy when using a fundamental instrument such as the dictionary and analyses students' relationship to dictionaries from a multifaceted perspective. First and foremost, the analysis is interested in revealing the students' appetite for meaning searching of the various unknown words in their technical materials. Secondly, the study inquires students' preference for paper-based or online dictionaries given that the moment when the questionnaire was applied was one whole year through the COVID 19 pandemics when school had been predominantly online. Then, the study examines the students' awareness of features of online dictionaries in order to check the informativeness on the dictionary features and use by teachers or schools. Therefore, the students are questioned about the features they know the dictionaries have. Subsequently, the focus is reduced to one conspicuous feature in the online dictionaries, namely, the pronunciation. The standing out feature of pronunciation is deemed by comparison to the paper-based dictionaries that share the same feature, but they presuppose supplementary phonetic knowledge that would enable users to decipher the correct pronunciation of the word. Out of all the features in an online dictionary, pronunciation is prominent as, by comparison to paper-based dictionary, it readily contributes to students' correct pronunciation. Last but not least, the students were questioned about their latest online dictionary access in terms of what made them access it. The reason behind this question is an indicator of their semi-controlled (school-guided or teacher-imposed) or independent (ensuing from personal interests) access of the dictionary.

\section{Online dictionaries or a way to avoid learning slow down}

Learning is a natural datum which presupposes imitation of others' habits (in behaviour) and verbal patterns or wording (in speech). When institutionalized, learning, though still imitative at times, becomes more structured and learners take advantage of an array of tools which help learning with demonstrations, further explanations, and examples (Ranalli 2013, 82). Laboratories enhance practical learning, gadgets facilitate an easy and cheap access to knowledge and dictionaries open new worlds to secrets of languages otherwise hidden to the uninitiated. As yet, the dynamics of modernity has delivered products that combine the traditional 
and the progress in order to provide updated, ready-to-use, easily accessible tools that facilitate learning. Such a tool is certainly the online dictionary that will become the focal centre of this paper.

But, what is it that learners should know about online dictionaries? What are the features that learners should know for their effective use of a dictionary? In order to answer these questions an accessible definition of what a dictionary is will be provided so as to extract a dictionary's content and utility. Bergenholtz (2012, 30 ), in an attempt at finding an as comprehensive as possible definition of what a dictionary is, has provided the following definition:

Lexicographic reference work containing dictionary articles related to individual topics or elements of language, and possibly several outer texts as well, which can be consulted if someone needs assistance with text reception, text production or translation or would simply like to know more about a word, part of a word or a combination of words.

Bergenholtz's definition may not be the most complex, but it certainly reflects the author's concern for accuracy when defining certain terms. Thus, Bergenholtz proves very judicious when defining the items in dictionaries as articles not words that may serve as a helper when confronted with unknown words in one's own language or in foreign languages.

With a growing need for the establishment of equivalences between languages, dictionaries (Béjoint 1984, 210) have turned into authorities that facilitate the translation from and into languages, covering a variety of data ranging from word origin, form, gender, number to synonyms, antonyms, idioms, etc. By further additions dictionaries turned into encyclopaedic collections of word data drastically reducing their accessibility and manual handling. Yet, new times bring along new ways and thus, dictionaries have undergone the transition to onlineness which has facilitated dictionary access and manoeuvrability (Múller-Spitzer \& Koplenig 2014, 164). Important dictionaries have split their addressability between the paper-based and online versions targeting a wide range of end-users, thus popularising dictionary usage among learners.

\section{Online dictionary skills}

Nevertheless, easiness in accessibility does not really mean that dictionary usefulness is actually reached as there is a long way between a dictionary's online existence and its becoming a really useful tool bringing a serious contribution to the 
learning of any language (Summers 2013, 120). There are some elements which are meant to render dictionaries really useful to learners in particular (Cowie 1983, 137) and to learning, in general. As simplistic as it may seem, no one can expect learners to start using dictionaries without any previous instruction on dictionary symbols and handling (Alhaisoni 2016, 31). Effectiveness of usage is yet another lesson that needs teaching as, though perceived as a deductible skill, using a dictionary requires training rather than intuition. Intuitive as they may be, dictionaries entail solid knowledge (Béjoint 2000, 42) as far as making the best of them is concerned and a real appetite for the discovery of the language in study. Teaching dictionary skills (Bae 2015, 46) is indisputably a desirable action as it will maximize learner autonomy and will certainly improve language efficiency in students.

Among the elements that should be taught about dictionaries is that dictionary articles may have more than one meaning which means that learners should discriminate between the multiple meanings of the word they are interested in and choose the one that fits their context (Múler 2002, 719). When confronted with a word they meet for the first time learners would rather be able to identify the technical/ non-technical (general English) use of a word as that might contribute to their correct selection of a word's meaning from a dictionary. To exemplify, in the context 'At high engine speed, physical breakage and piston ring flutter can occur, resulting in power loss or even engine destruction. Piston ring flutter occurs when the rings oscillate vertically within the piston grooves they reside in' learners should recognize the indicators of the technical context (Liu and Lei 2019,115$)$ that could help them decide on the right meaning of 'flutter'. Yet, that is not all that it is to it. Additionally, learners should be trained to identify the speech part the word they look for is. Making the decision on what the word is might strongly influence the correctness of their answer as English has got a number of difficulties that appear from either the noun and the verb having the same form (as in 'to gauge' and 'gauge') or the noun having an unexpected form from that of the verb. Thus, as the meaning of a word varies according to the context and to the speech part, learners should be trained to check carefully the data provided by online dictionaries in as far as these two aspects are concerned.

Although technology-wise, learners should be trained on how to effectively and efficiently use the online dictionary. Generously displayed, online dictionaries are highly organized by meaning and by speech part. The meanings of an article are gradually displayed from the most common to the least common accompanied by numerous examples meant to help students identify how the word functions in the sentence, what preposition it might be followed by, etc. The difference between the various meanings is easily graspable and online dictionaries make sure that 
every new meaning is highlighted in order to draw the attention of the interested. When the speech parts have the same form, the passage from one speech part to the other is clearly marked so as to clearly delineate the two speech parts.

Working with students who specialize in a domain such as engineering will inevitably add further challenges to online dictionary usage (Chung and Nation 2004, 252). Leaving aside the dispute on what technical vocabulary is, engineering students need live demonstrations of how dictionaries can help them. Seeing is believing for the students who apply science in all their classes that might emphasize the pragmatic and strongly-applied character of their studies. Yet, despite engineering students' empiric learning method, they demonstrate a rather reduced availability when working with an online dictionary. They have many inaccuracies about English pronunciation, word meaning, grammar accuracy, yet, they prefer to avoid checking in online dictionaries which, although readily available on their mobile phones, will be left unchecked and the mistakes will perpetuate. Still, observational reporting can be challenged by the questionnaire meant to discover engineering students' usage of online dictionaries in pandemic times.

\section{Questionnaire description}

The questionnaire applied was made of five multiple choice and one openended questions all directed at discovering engineering students' attitudes to online dictionary use in the COVID pandemics. The participation in the questionnaire was voluntary and anonymous and it was answered upon the completion of a two-semester technical English course where the dictionary use had been introduced to students with a special emphasis on the progress they could make based on dictionary word checking. As all the activities were online, class-, group- or individual work entailed consistent dictionary access for various reasons from among which the following were the most frequent: checking for other speech parts derived from the words provided, checking the spelling of rather infrequent technical words, checking the pronunciation of new unknown words, checking for prepositions, verifying the meaning of idioms or phrasal verbs, etc. These activities were online and simultaneous, which means that they were under the permanent surveillance of the teacher who would encourage dictionary use. The ultimate purpose of the test is to actually check whether the regular classroom preoccupation for online dictionary access had transformed into a personal habit. 


\subsection{Online dictionaries and unknown words}

The first question in the questionnaire was meant to obtain the students' options as to what they do when facing the situation of encountering an unknown word. The choices the students were provided to select from covered a range of options that people usually retort to when confronted to a similar situation. Hence, despite the practice and the students' awareness of the advantages they have when accessing the online dictionary, most students prefer to deduce the meaning of the unknown word in the context although the context may not be in all cases a great helper in deciphering the meaning of a word. Not infrequent were the situations when students mispronounced basic words in engineering although they had been presented the easiness and the advantages of checking pronunciation online. Less than half of the students admitted to be using the online dictionary when finding an unknown word. Though not really representative for the group of students participating in the research the choices 'I don't look the word up in a dictionary because it takes too much time' and 'I don't care much about learning new words' show that there are students who do not bear any interest in perfecting their English knowledge. The preference for the deduction of the word's meaning in the context may be interpreted as convenience. On the other hand, it may also stand for an insufficient practice as dictionary skills are still considered inaccessible, heavily related to bulky paper-based dictionaries. The transfer of the dictionaries in the online is a chance that should be exploited to the maximum and students should be encouraged to access it as often as possible.

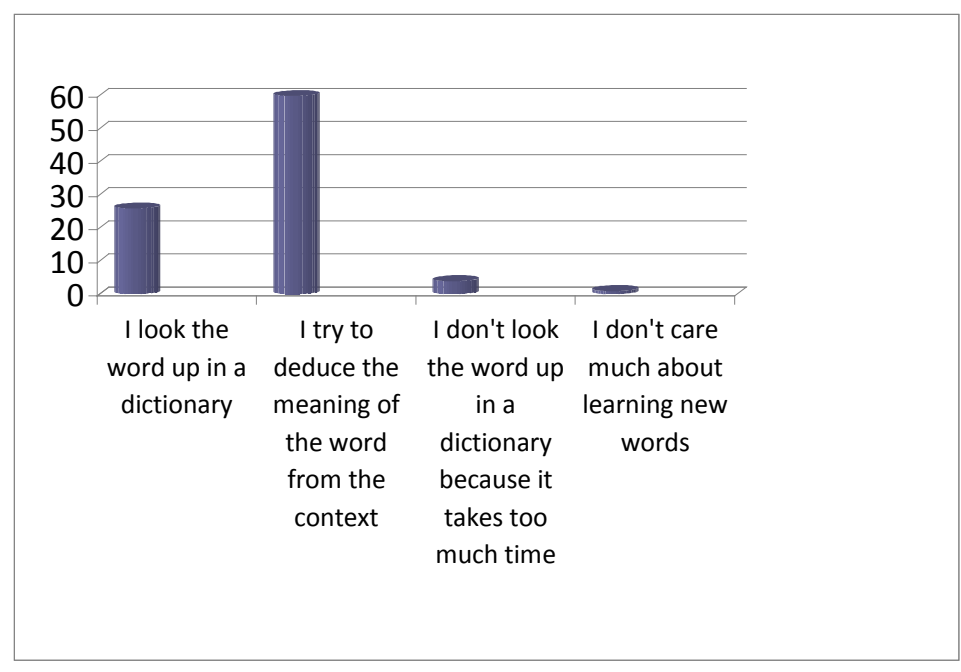

Figure 1. Students' attitude to unkown words 


\subsection{Paper-based or online dictionaries?}

The next two questions are intentionally meant to kindle students' interest in balancing the amount of research they do in paper-based and online dictionaries. Taken separately, question 2 collects data about the students' possession of and interest in paper-based dictionaries. The answers agglomerate in the area of an occasional use of a paper-based dictionary with a view to checking data in a dictionary. Data that speak volume about the physical existence of dictionaries in the case of engineering students can easily be extracted from the chart. The reduced dictionary use owes majorly to the absence of paper-based dictionaries which used to be rarities before the introduction of online dictionaries. The price of paper-based dictionaries, their scarcity and reduced popularisation would implicitly lead to a reduced access to data otherwise vital to language learning. The choice that scores second is not negligible as it reflects a pervasive way of relating to the paper-based dictionaries of the engineering students participating in the research.

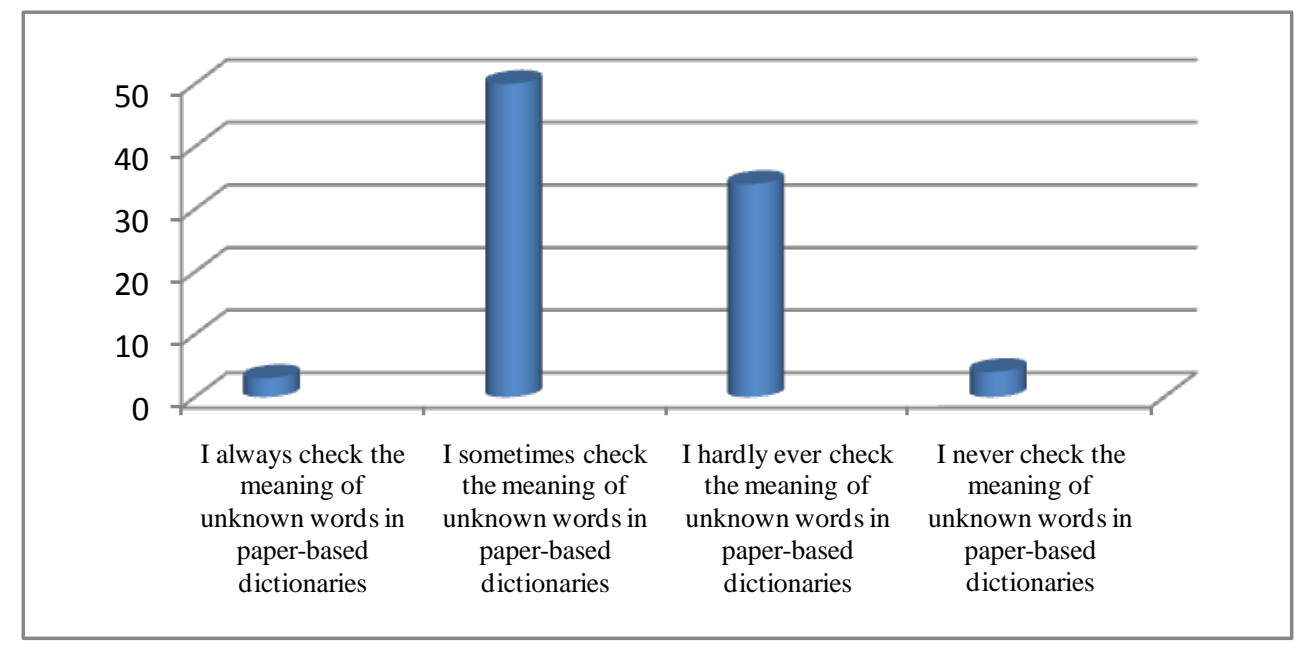

Figure 2. Students' preferences for online and paper-based dictionaries

The third question, though compiling data about the use of online dictionary solely, provides solid grounds for a comparison between the use of paper-based and online dictionaries. To begin with, the data show that the majority of students check unknown words in online dictionary with another representative share that 
'sometimes' checks the information in online dictionaries. Summed up, the two choices represent 87 out of the total of 92 participants. The number of students who do not access online dictionaries is reduced and the possible causes for their not accessing the online dictionaries may be either inappropriate technology, or a faint interest in English or insufficient exposure to information epitomizing the importance of dictionary use. The effortless access of online dictionaries in a period when mobile phone have become an affordable commodity for most people does impact students' access to data that might contribute to a better learning of the language. What is more, free access to online dictionaries facilitates foreign languages exposure as there would be fewer tax-paying students willing to spend their money for dictionary access. Notwithstanding, pupils or students should not be expected to discover the advantages of using online dictionaries by themselves. Dictionary use should be taught by teachers, popularized and students encouraged to use it as often as possible as a means of valuable discovery. Though engineering students may be primarily interested in STEM subjects, they equally understand the importance of learning foreign languages as an easy way of accessing information produced in a culture or language other than theirs. The blatant difference that is immediately observable is the clear choice that students make in favour of online dictionary when it comes to checking the meaning of an unknown word in a paperbased or online dictionary. If in the case of the paper-based dictionary only three students always check the unknown word, in the case of the online dictionary there are 49 students always checking the unknown word. What is different between these two actions is not the action itself, but the means that facilitates the access to the unknown word which shows that the easier the access, the more accessed the source. When comparing the second choice where the key word is 'sometimes' fifty students access the paper-based dictionary, whereas 38 students access the online dictionary. Consequently, students' first choice is accessing the online dictionary and the second to access the paper-based dictionary. 


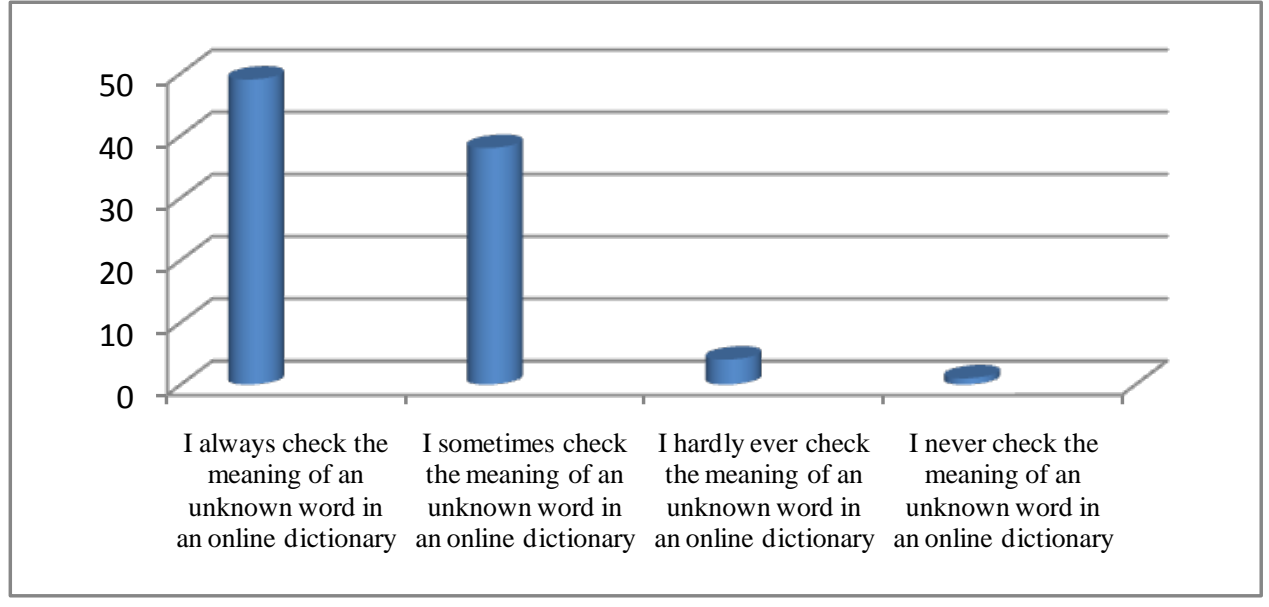

Figure 3. Frequency of online dictionary accessing for unknown words

\subsection{Pronunciation: to check it or not?}

One question included in the questionnaire that bears a great importance for the engineering students is the pronunciation of new technical words which does represent a challenge for students. As speaker of English, mispronouncing words may lead to disastrous consequences for science. International cooperation on research projects is guaranteed by communication in languages that have attracted a majority of speakers that can handle that language comfortably. Or disregarding a vital aspect such as pronunciation bringing as a reassuring factor the ignorance of others or the importance of transmitting one's message whatever the deficiencies may eventually lead to communication failure. Checking the pronunciation of new words in an online dictionary is one of the first pieces of advice students are given as it notably facilitates a correct pronunciation. Pronouncing words where to apply rules applicable in other situations is certainly counterproductive and might entail misunderstandings in communication. To exemplify the above, a common error that students commit is the pronunciation of the word 'engine', a word largely used in the mechanical engineering domain. Students mispronounce the word as they apply the pronunciation they learnt at the beginning of their English studies of the English alphabet. Thus, they learnt that ' $i$ ' is pronounced as [ai] which makes them pronounce the word 'engine' as [en.dzaın] instead of [en.dzın]. If this mispronunciation were met only once, it would have been interpreted as a slip, but 
the mispronunciation is predominant with only a few students pronouncing the word correctly. The students participating in the study have been instructed at the beginning of the semesters about where to look for the correct pronunciation, about the advantages of learning the correct pronunciation of words and it was all up to them to actually take advantage of this feature of online dictionaries. Yet, as the students admit in the questionnaire, there is no majority involved in checking word pronunciation for new words. The number of students who do not usually check pronunciation is significant representing almost a third of the participants in the study, in this way perpetuating possible pronunciation mistakes. Dictionary skills are those skills by which students learn how to handle a dictionary, where to look for a particular type of information, how to discriminate between various speech parts, but it should not limit to that. Though it may seem unimportant, students should be encouraged to access online dictionaries as often as possible as this will transform dictionary use into a habitual activity that will no longer be perceived as an activity that puts students out of their comfort zone.

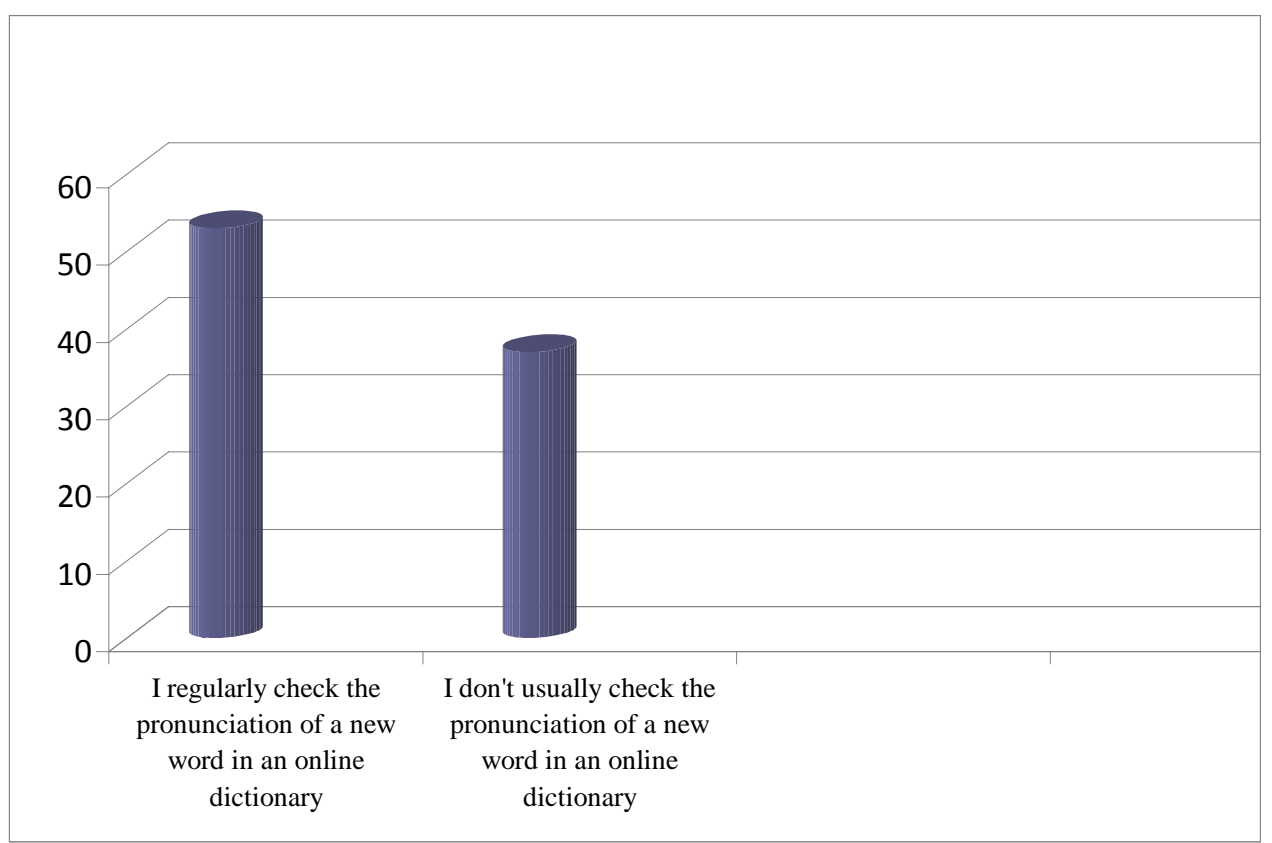

Figure 4. Students' pronunciation checking habits 
At the end of a year's instruction, the students are questioned about the reasons that they access an online dictionary for. Unlike the other questions where students are restricted to the choices introduced in the questionnaire, this is an open-ended question which allows participants to indicate the purpose of their latest dictionary accessing. Their reasons are among the expected ones as apparently their dictionary use is mostly associated to university-related interests. In fact, they mention preparing for university English projects as this is part of their semester assessment. Another reason is finding a car component for either their seminar projects or for their lecture activities. The third reason is checking dictionaries in order to discover the meaning of unknown words which they may find in the various technical texts they are exposed to during the lecture. Though rare, some students mentioned the situations when they use the online dictionary with a view to checking the correctness of a word's form when they need to produce their own technical texts. Pronunciation is not left aside and students indicate that sometimes they access online dictionaries in order to discover the correct pronunciation of a new word. After identifying the participants' latest reasons for online dictionary use a few ideas are worth mentioning:

- Firstly, they have understood that online dictionaries are tools readily available that they should take advantage of as often as possible

- Secondly, they use online dictionaries for activities that are largely related to their university English-related classes

- Thirdly, though that was not the aim of the research, it is hard not to notice that students do not mention any other activities when accessing online dictionaries

- Fourthly, accessing dictionaries for a range of data about a language signals that students have understood the importance of dictionaries that they get used to using more and more frequently

\subsection{Dictionary features known by students}

After the introduction of online dictionaries at the beginning of the university year, after an entire year's online classes where the advantages of online dictionaries have been demonstrated and frequently used as it has been at hand to retort to them when working on the projects, students are presented a list of features that dictionaries have and they have been asked to tick the ones they know online 
dictionaries to have. As the results show, the participants are more familiar with some features (explanation of the word's meaning, pronunciation, examples and translator), whereas other features such as level of complexity, idioms, word lists, and quizzes score very low as they are known to a very reduced number of students from the participating student population. This repartition of students' knowledge related to dictionary contents is highly helpful as, when considered appropriate, teachers might direct students' attention to these features that are underestimated and which equally provide precious information for the students and for whoever might be interested in learning more English.

\section{Features of online dictionaries that students are aware of}
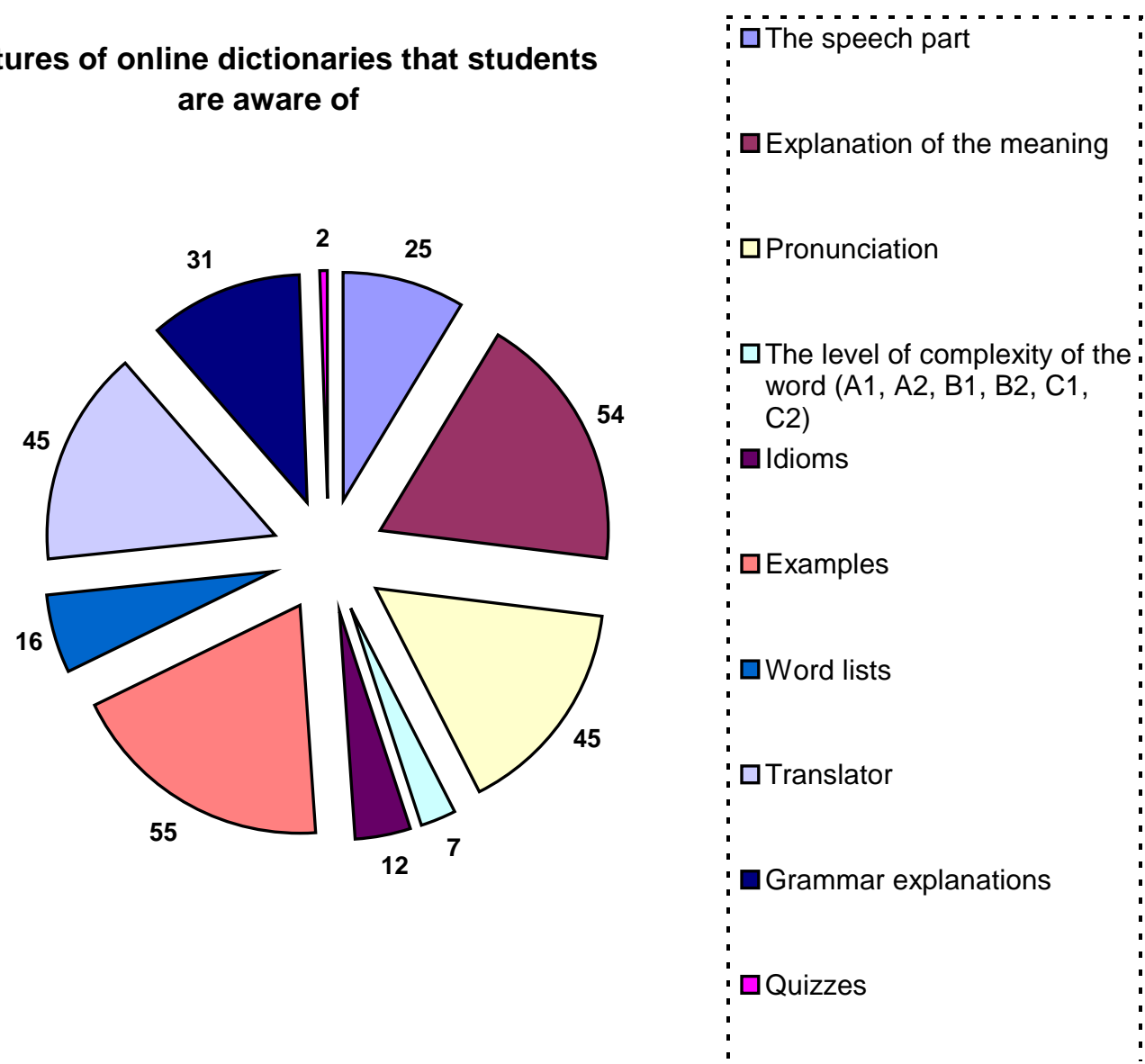

Figure 5. Features of dictionaries known by students 


\section{Conclusion}

This study has been aimed at popularizing the need for teaching dictionary skills to students as, though it seems accessible to everybody, dictionary work is a habit that requires practice before it becomes a routine. Students should know what dictionaries have to offer and teacher-organised activities need to prove the effectiveness of dictionary use. The study is equally collecting data about student routines when learning foreign languages by means of dictionary. Thus, the data have revealed that students prefer to deduce the meaning of the word in the context taking the risk of misinterpreting the context, consequently, the meaning of the word. It is a signal that what has been done in the direction of getting students familiarized to using online dictionary hasn't been enough and that more should be done in this direction. The study has also indicated that students prefer online dictionaries to paper-based dictionaries and they consistently claim using them in the study of English. Somehow unsurprisingly, students have a reserved attitude to checking pronunciation, which is easily noticeable when interacting with them. Slightly over $50 \%$ of the respondents manifested their interest and constant preoccupation for a correct pronunciation of English words. As dictionaries have quit providing basic information and as they become more and more complex, the study targeted at exposing the students' awareness of the profuse information dictionaries offer about the articles in them. The students' answers have showed that some dictionary features are better known than others, which again beckons the necessity to transform dictionary skills classes into mandatory classes with an important contribution to the dictionary's comprehensive use by the students.

\section{References}

Bae, Susanna. 2015. "A course in dictionary use for Korean EFL teachers." Lexicography ASIALEX 2: 45-69.

Béjoint, Henri. 1984. "The Teaching of Dictionary Use: Present State and Future Tasks." In Ein internationales Handbuch zur Lexicographie ed. by Franz Hausmann, Oskar Reichmann, Herbert Wiegang, and Ladislav Zgusta, 208215. Berlin: Gruyter.

Béjoint, Henri. 2000. Modern Lexicography: An Introduction. Oxford: Oxford University Press.

Bergenholtz, Henning. 2012. “What is a Dictionary?”. Lexikos 22(1): 20-30.

Chung, Teresa Mihwa and Paul Nation. 2004. "Identifying technical vocabulary". System 32: 251-263. 
Cowie, Anthony Paul. 1983. "English Dictionaries for the Foreign Learner". In Lexicography: Principles and Practice ed. by Reingard Hartmann, 135-144. London: Academic Press.

Dilin, Liu and Lei Lei. 2019. "Technical vocabulary". In The Routledge handbook of vocabulary studies ed. by Stuart Webb, 111-124. London and New York: Routledge.

Müller, Vera. 2000. "The use of dictionaries as a pedagogical resource in the foreign language classroom". In Euralex 2002 Proceedings, 717-721.

Múller-Spitzer, Caroline and Alexander Koplenig. 2014. "Online dictionaries: expectations and demands". In Using online dictionaries ed.by Caroline, Múller-Spitzer, 143-188. Berlin: De Gruyter.

Ranalli Jim. 2013. "Online strategy instruction for integrating dictionary skills and language awareness". Language Learning \& Technology 17(2), 75-99.

Summers, Della. 2013. "The role of dictionaries in language learning". In Vocabulary and Language Teaching ed. by Ronald Carter and Michael McCarthy, 111-125. London and New York: Routledge. 